\title{
The role of plasma gelsolin in cardiopulmonary bypass induced acute lung injury in infants and young children: a pilot study
}

ShanShan Shi ${ }^{1}$, Chi Chen², DongYan Zhao ${ }^{2}$, XiWang Liu², BaoLi Cheng ${ }^{3}$, Shuijing Wu³ ${ }^{3}$ Ru Lin², LinHua Tan', XiangMing Fang ${ }^{3^{*}}$ and Qiang Shu ${ }^{2 *}$

\begin{abstract}
Background: Acute lung injury (ALI) induced by cardiopulmonary bypass (CPB, CPB-ALI) is a common and serious complication after cardiac surgery. And infants and young children are more prone to CPB-ALI. The purpose of this study was to investigate the perioperative changes of plasma gelsolin (pGSN) in patients below 3years of age with cardiac surgeries and CPB, and determine whether pGSN are associated with the occurrence and severity of CPB-ALI.

Methods: Seventy-seven consecutive patients $\leq 3$ years of age with congenital heart diseases (CHD) performed on open heart surgery with CPB were finally enrolled, and assigned to ALI and non-ALI groups according to the American-European Consensus Criteria. Plasma concentrations of gelsolin and total protein were measured at following 8 time points: before CPB (a), after CPB (b), 2 hours after CPB (c), 6 hours after CPB (d), 12 hours after CPB (e), 24 hours after CPB (f), 48 hours after CPB (g) and 72 hours after CPB (h).

Results: Twenty-seven (35.1\%) patients developed CPB-ALI in the study, including eleven (14.3\%) patients with ARDS. The earliest significant drop of pGSN and normalized pGSN ( $\left.p G S N_{N}\right)$ of ALI group both occurred at 6 hours after CPB ( $p=0.04$ and $p<0.01$ ), which was much earlier than those of non-ALI group (48 hours, $p=0.03$ and 24 hours, $p<0.01$ ); PGSN of ALI group before CPB and 6 hours after CPB were both significantly lower than those of non-ALI group ( $p<0.01$ ); PGSN of ALI group before CPB and 6 hours after CPB were both significantly lower than those of non-ALI group ( $p<0.01, p=0.04$ ); PGSN before CPB was the only independent risk factor predicting the occurrence of CPB-ALI (OR, 1.023; 95\% Cl, 1.007-1.039; $p<0.01)$ with an AUC of 0.753 (95\% Cl, 0.626-0.880); The optimal cutoff value of pGSN before CPB was $264.2 \mathrm{mg} / \mathrm{L}$, with a sensitivity of $58.3 \%$ and a specificity $94.7 \%$. And lower pGSN before CPB was significantly associated with the severity of CS-AKI $(r=-0.45, p<0.01)$.
\end{abstract}

Conclusions: Patients developing CPB-ALI had lower plasma gelsolin reservoir and a much more amount and rapid consumption of plasma gelsolin early after operation. PGSN before CPB was an early and sensitive predictor of CPB-ALI in infants and young children undergoing cardiac surgery, and was negatively correlated with the severity of CPB-ALI.

Keywords: Plasma gelsolin, Acute lung injury, Cardiac surgery, Cardiopulmonary bypass, Infant, Young children, Congenital heart disease

\footnotetext{
*Correspondence: xiangming_fang@163.com; shuqiang@zju.edu.cn

${ }^{3}$ Department of Anesthesiology, the First Affiliated Hospital, Medical College,

Zhejiang University, No. 79, Qingchun Road, Hangzhou 310003, P R China

2Department of Thoracic \& Cardiovascular Surgery, Children's Hospital,

Medical College, Zhejiang University, and Zhejiang Key Laboratory for

Diagnosis and Therapy of Neonatal Diseases, No. 57, Zhugan Lane,

Hangzhou 310003, P R China

Full list of author information is available at the end of the article
}

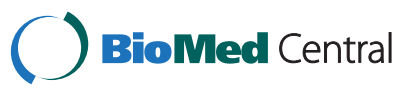

(C) 2014 Shi et al.; licensee BioMed Central Ltd. This is an Open Access article distributed under the terms of the Creative Commons Attribution License (http://creativecommons.org/licenses/by/2.0), which permits unrestricted use, distribution, and reproduction in any medium, provided the original work is properly credited. The Creative Commons Public Domain Dedication waiver (http://creativecommons.org/publicdomain/zero/1.0/) applies to the data made available in this article, unless otherwise stated. 


\section{Background}

Acute lung injury induced by cardiopulmonary bypass, a common and serious complication in patients undergoing cardiac surgery necessitating $\mathrm{CPB}$, may impair both lung mechanics and gas exchange, and becomes an important factor of morbidity and mortality after surgery [1,2]. 2\% of those patients may develop into acute respiratory distress syndrome (ARDS) resulting in a mortality of $15 \%$ to $50 \%$ [3]. Infants and children are more prone to CPB-ALI which is associated with postoperative pulmonary complications, prolonged mechanical ventilation, as well as longer ICU time and hospital resource utilization [4,5]. Therefore, there is increasing interest in developing some effective biomarkers for prediction of CPB-induced ALI in infants and children, which would be helpful for early diagnosis and decision-making.

Gelsolin, a protein of $82-84 \mathrm{KDa}$, is the founding member of gelsolin protein superfamily, as a cytoplasmic as well as a plasma isoform, can bind, sever and cap actin filaments. Plasma gelsolin, primarily secreted by myocytes, is believed to function as an important actin scavenger in the circulation [6-8]. Besides, emerging data have demonstrated that pGSN, as an inflammatory mediator-binding protein, also functions as a lipid carrier with strong binding affinity to several plasma lipids such as lipopolysaccharide exdotxin, lipoteichoic acid, lysophosphatidic acid, $\beta$-amyloid peptide and platelet-activating factor, etc., and plays a role in localizing inflammation and prevent systemic escape of pro-inflammatory lipids [9-12]. Consistent with these proposed functions, declining pGSN level has be proved to be associated with a variety of acute clinical conditions, such as sepsis, myocardial infarction, major trauma, burn, allogeneic stem cell transplantation and acute liver injury, etc. And more importantly, pGSN levels are inversely related to the clinical outcome under these conditions [13-18].

For systemic inflammatory response syndrome (SIRS) is the origin of CPB-ALI, we speculated that pGSN might play a role in the development of CPB-ALI. The purpose of this study was to investigate the perioperative changes of pGSN level in patients below 3 years of age undergoing cardiac surgeries with $\mathrm{CPB}$, and determine whether pGSN levels are associated with the occurrence and severity of CPB-ALI.

\section{Methods \\ Protocol}

The study was conducted in a 20-bed Surgical ICU (SICU) from November 2012 to March 2013 at the children's hospital, Medical College, Zhejiang University, P. R. China. The present study was approved by local hospital ethics committee (Medical Ethics Committee, Children's Hospital, Medical College, Zhejiang University), and written informed consents were obtained from their parents.
Seventy-seven consecutive patients aged $\leq 3$ years (including 3 neonates) with congenital heart diseases undergoing open heart surgery with $\mathrm{CPB}$ were finally enrolled into the study. Patient with pneumonia, liver/renal dysfunction, major chromosomal abnormalities, need for mechanical ventilation before surgery, premature babies, or low cardiac output syndrome after surgeries was excluded from the study.

Anesthesia and $\mathrm{CPB}$ procedure were managed according to the standard protocol. Myocardial protection was achieved using cold blood cardioplegic solution unless otherwise indicated. The patients were transferred to SICU immediately after surgery. Each patient was monitored continuously for hemodynamic and respiratory data. Blood gas analysis was performed routinely pre-, intra-, and post-operation. All the patients admitted to SICU were ventilated with initial inspiratory oxygen fraction $\left(\mathrm{FiO}_{2}\right) 50 \%$ and initial positive end expiratory pressure (PEEP) $3 \mathrm{cmH}_{2} \mathrm{O}$, and then adjusted to maintain normocapnia and oxygen saturation $\left(\mathrm{SaO}_{2}\right)$ higher than 95\% with lowest $\mathrm{FiO}_{2}$ and most appropriate PEEP. And chest radiograph was performed every 24 hours.

The criteria of weaning from invasive ventilation in our unit are provided in detail in Additional file 1. Noninvasive ventilation (continuous positive airway pressure, CPAP) was used immediately after thacheal extubation in patients at high risk of extubation failure (EF) (Additional file 1), or started when acute respiratory failure appears after extubation. The initial CPAP setting was accorded to the each patient's age and weight, and adjusted by the clinical status. Patients not responding successfully to CPAP were reintubated according to the criteria provided in Additional file 1, and the decision was made by the attending physicians.

\section{Definition of CPB-ALI}

Patients were categorized into CPB-ALI group if they met the American-European Consensus Criteria within $24 \mathrm{~h}$ after surgery [19]. The diagnosis was made by the physician blind to the study.

\section{Data and blood sampling collection}

Whole blood samples $(3 \mathrm{ml})$ were obtained from patients at following time points: before $\mathrm{CPB}$ (a), after $\mathrm{CPB}$ (b), 2 hours after CPB (c), 6 hours after CPB (d), 12 hours after CPB (e), 24 hours after CPB (f), 48 hours after CPB (g) and 72 hours after CPB (h), and were collected in EDTA-containing tubes. After being centrifuged at $2500 \mathrm{~g}$ for 5 minutes at $4^{\circ} \mathrm{C}$, plasma samples were frozen at $-80^{\circ} \mathrm{C}$ until analysis. PGSN levels were measured using an ELISA kits (USCN, Wuhan, P. R. China) according to the manufacturer's instruction. The plasma total protein amount (TP) was measured at each time point by an 
auto-biochemistry analyzer (Modular Analytics, Roche, USA) for pGSN normalization.

The clinical variables included sex, age, age distribution, weight, risk adjustment for surgery for congenital heart disease (RACHS-1), CPB time, aortic cross-clamp time, nadir $\mathrm{HCT}$ (\%) during $\mathrm{CPB}$, ultrafiltrated volume removal (UVR), positive fluid balance after $\mathrm{CPB}$, need for transfusion within 24 hours after $\mathrm{CPB}$, nosocomial pneumonias (NF), extubation failure (EF), as well as mechanical ventilation duration, need for CPAP, ICU stay, hospital stay and hospital death. The definitions for the clinical variables are provided in Additional file 2.

\section{Statistical analysis}

Continuous variables were tested for normal distribution by one-sample Kolmogorov-Smirnov test, and were expressed as mean \pm SD if normally distributed, and otherwise, as median (interquartile range). Student's $t$-test or the Mann-Whitney $U$-test was used to determine the significant difference of continuous variables between two groups; $\chi^{2}$ test was used for the comparison of categorical variables. The both changes of pGSN and pGSN ${ }_{\mathrm{N}}$ (pGSN/ TP ratio, $10^{-3}$ ) level over times of each group were analyzed by two-way ANOVA, and an analysis of covariance procedure (ANCOVA) was used to test the differences of both pGSN and pGSN $_{\mathrm{N}}$ between two groups. Logistic regression analysis was used to identify the independent risk factors for CPB-ALI. The preoperative, intraoperative and early postoperative variables with a $p$ value less than 0.1 were entered into the logistic model, including age, age distribution, weight, positive fluid balance after CPB, TP and pGSN before CPB. Area under the ROC curve was used to assess how well the factors diagnose CPB-ALI. A Pearson or Spearman correlation test was performed to determine the correlation between pGSN and severity of CS-AKI and other clinical outcomes. A $p$ value less than 0.05 was considered to be statistically significant. Statistical analysis was performed using SPSS 16.0 (SPSS Inc, Chicago, IL, USA) software version.

\section{Results}

\section{Clinical outcomes}

During the study period, a total of 77 patients aged $\leq 3$ years were enrolled in the study. Among the 77 patients, 27 (35.1\%) developed CPB-ALI, including eleven (14.3\%) patients with ARDS. As shown in Table 1, no differences were observed in gender distribution, RACHS-1 score, $\mathrm{CPB}$ time, aortic cross-clamp time, nadir HCT during $\mathrm{CPB}$, UVR, need for transfusion within 24 hours after $\mathrm{CPB}, \mathrm{EF}$ or NF incidence and hospital stay between the two groups. However, compared with patients without CPB-ALI, the patients with CPB-ALI were significantly younger in age, especially in patients $<1$ year of age, lighter in weight, higher incidence of positive fluid balance after
CPB. In addition, the durations of mechanical ventilation and ICU stay of ALI group were both longer than those of non-ALI group; the patients with CPB-ALI were more likely to require CPAP after thacheal extubation. No patients died in hospital in this pilot study.

\section{The perioperative changes of plasma gelsolin and total protein}

Plasma gelsolin levels were showed in Table 2, both as absolute value (pGSN) and normalized value $\left(\mathrm{pGSN}_{\mathrm{N}}\right)$. For the plasma total protein level after CPB decreased dramatically $(p<0.01)$, both pGSN and $\mathrm{pGSN}_{\mathrm{N}}$ levels were used for univariate analysis. In the ALI group, both of the earliest significant drop of pGSN and $\mathrm{pGSN}_{\mathrm{N}}$ occurred at 6 hours after $\mathrm{CPB}$ compared with those of the preoperative levels (baseline level, $p=0.04$ and $p<0.01$ ), while the first remarkable drops of pGSN and $\mathrm{pGSN}_{\mathrm{N}}$ in non-ALI group occurred at 48 hours after CPB $(p=0.03)$ and 24 hours after $\mathrm{CPB}(p<0.01)$ respectively (Figure 1$)$.

The pGSN level of ALI group before CPB and 6 hours after $\mathrm{CPB}$ were $(122.6 \pm 24.6) \mathrm{mg} / \mathrm{L}$ and $(89.9 \pm 17.6) \mathrm{mg} / \mathrm{L}$, which were significantly lower than those of non-ALI group $[(176.4 \pm 54.5) \mathrm{mg} / \mathrm{L}, p<0.01$ and $(141.0 \pm 49.0) \mathrm{mg} / \mathrm{L}$, $p<0.01]$. Likewise, the $\mathrm{pGSN}_{\mathrm{N}}$ of ALI group before $\mathrm{CPB}$ and 6 hours after $\mathrm{CPB}$ were $(2.02 \pm 0.39) \times 10^{-3}$ and $(1.61 \pm 0.26) \times 10^{-3}$, which were also significantly lower than those of non-ALI group $\left[(2.77 \pm 0.89) \times 10^{-3}\right.$, $p<0.01$ and $(2.18 \pm 0.75) \times 10^{-3}, p=0.04$ ] (Table 2, Figure 2).

The TP level before surgery of ALI group was significantly lower than that of non-ALI group [(59.3 \pm 5.6$)$ vs. $(64.1 \pm 4.8), p<0.01]$.

\section{Low plasma gelsolin before CPB as a predictor for CPB-ALI} Logistic regression revealed that pGSN before $C P B$ was the only independent risk factor for predicting the occurrence of CPB-ALI (OR, 1.023; 95\% CI, 1.007-1.039; $p<0.01$ ) among the six factors (age, age distribution, weight, positive fluid balance after CPB, TP and pGSN before CPB). In the ROC analysis (Figure 3), the AUC of pGSN before CPB was 0.753 (95\% CI, 0.626-0.880). And the optimal cutoff for pGSN before CPB was $264.2 \mathrm{mg} / \mathrm{L}$, with a sensitivity of $58.3 \%$ and a specificity $94.7 \%$.

\section{Plasma gelsolin predict the severity of CPB-ALI}

Lower pGSN before CPB was significantly associated with the severity of CPB-ALI in this study (Figure $4, r=-0.45$, $p<0.01)$. Though age, age distribution, weight, positive fluid balance after CPB and TP before CPB were excluded from final multiple regression analysis, younger age, patients $\leq 1$ year of age, lighter weight and low total protein level before $\mathrm{CPB}$ were proved to be significantly correlated with the severity of CPB-ALI $(r=-0.335$, 
Table 1 Demographic and clinical characteristics of the patients enrolled in the study

\begin{tabular}{|c|c|c|c|c|}
\hline & Total & ALI $(n=27)$ & Non-ALI $(n=50)$ & $p$ \\
\hline Sex male n (\%) & $55(71.4)$ & 17(63.0) & $38(76.0)$ & $0.27^{C}$ \\
\hline Age (months) & $9.1 \pm 6.8$ & $5.8 \pm 4.5$ & $10.9 \pm 7.2$ & $0.001^{\mathrm{a}}$ \\
\hline Age distribution & & & & $0.03^{C}$ \\
\hline $0-1$ year old & 54 & 23(42.6) & $31(57.4)$ & \\
\hline $1-2$ years old & 19 & $4(21.1)$ & $15(78.9)$ & \\
\hline $2-3$ years old & 4 & $0(0)$ & $4(100)$ & \\
\hline Weight (kg) & $7.3 \pm 2.2$ & $6.0 \pm 1.8$ & $8.0 \pm 2.1$ & $0.001^{a}$ \\
\hline RACHS-1 & & & & $0.37^{c}$ \\
\hline 1 & 10 & 3 & 7 & \\
\hline 2 & 63 & 21 & 42 & \\
\hline$\geq 3$ & 4 & 3 & 1 & \\
\hline CPB time (min) & $69.4 \pm 23.3$ & $74.6 \pm 22.1$ & $66.7 \pm 23.7$ & $0.23^{\mathrm{a}}$ \\
\hline Aortic cross clamp time (min) & $50.1 \pm 19.6$ & $46.5 \pm 17.7$ & $44.2 \pm 20.7$ & $0.68^{\mathrm{a}}$ \\
\hline Nadir HCT during CPB (\%) & $25.3 \pm 2.7$ & $25.2 \pm 2.3$ & $25.2 \pm 3.0$ & $0.98^{\mathrm{a}}$ \\
\hline Positive fluid balance after CPB (\%) & $55(71.4)$ & 24(88.9) & $31(62.0)$ & $0.03^{C}$ \\
\hline Need for transfusion within 24 hours after CPB (\%) & $6(7.8)$ & $2(7.4)$ & $4(8.0)$ & $0.93^{\mathrm{C}}$ \\
\hline Nosocomial pneumonias (\%) & $15(19.5)$ & $6(22.2)$ & $9(18.0)$ & $0.58^{c}$ \\
\hline CPAP (\%) & 10(13.0) & $9(33.3)$ & $4(8.0)$ & $0.04^{c}$ \\
\hline EF (\%) & $3(3.9)$ & $3(11.1)$ & $0(0)$ & $0.12^{C}$ \\
\hline MV time (hour) & $24(3 \sim 446)$ & $26(4 \sim 446)$ & $6.5(3 \sim 189)$ & $0.001^{b}$ \\
\hline SICU stay (day) & $5(2 \sim 34)$ & $9.2 \pm 6.6$ & $4(2 \sim 34)$ & $0.001^{b}$ \\
\hline Hospital stay (day) & $23.4 \pm 10.0$ & $26.1 \pm 11.0$ & $21.9 \pm 9.2$ & $0.15^{\mathrm{a}}$ \\
\hline Hospital death (\%) & 0 & 0 & 0 & $0.77^{C}$ \\
\hline
\end{tabular}

Continuous variables were expressed as the mean \pm SD or median (interquartile range) if appropriated. Categorical variable were expressed as number of patients (\%).

${ }^{a}$ : Student's $t$-test; ${ }^{\text {b. }}$ Mann-Whitney $U$-test; ${ }^{c}: \mathrm{X}^{2}$ test.

RACHS-1 = Risk Adjusted Classification for Congenital Heart Surgery; ALI = acute lung injury; $C P B=$ cardiopulmonary bypass; $M V=$ mechanical ventilation; $\mathrm{CPAP}=$ Continuous positive airway pressure; $\mathrm{EF}=$ Extubation failure; SICU = surgery intensive care unit; UVR= ultrafiltered volume removal.

$p<0.01 ; r=-0.383, p<0.01 ; r=-0.441, p<0.01$ and $r=-0.395, p<0.01)$.

\section{Discussion}

The lungs are proposed to be one of most "sensitive" organ to the SIRS, especially in pediatric population [20]. The incidence of CPB-ALI of this cohort was $35.1 \%$, and $14.3 \%$ of patients developed ARDS, which was much higher than that of adult population. In univariate analysis, we found that weight was much lower in ALI group, and they were much younger than patients without ALI. The patients' weight and age of this study were significantly correlated with the severity of CPB-ALI $(r=-0.441, p<0.01$; and $r=-0.335, p<0.01)$. And the patients below 1 year old were especially prone to CPB-ALI compared with elder children (42.6\% vs. $21.1 \%)$, and was also strongly correlated with the severity of CPB-ALI $(r=-0.383, p<0.01)$. Furthermore, we also demonstrated that the preoperative plasma protein level of ALI group was much lower than that of non-ALI group $(p<0.01)$, and patients with ALI were vulnerable to positive fluid balance after CPB $(p=0.03)$. So, it seems that bronchopulmonary immaturity, hypoproteinemia, additional fluid retention worsens its inability to adapt the environment of systemic inflammatory response provoked by $\mathrm{CPB}$, which might consequently aggravate the increase of permeability, pulmonary vascular resistant and the changes of lung surfactant, and exacerbate lung disturbances early after surgery [2,3,21]. Though transfusion of blood products during or after surgery had been proved to be a strong risk factor of acute lung injury and might associated with increased mortality in long-term follow-up [22-24], there were no significant differences of nadir HCT during $\mathrm{CPB}$ and incidence of transfusion early after surgery between two groups in our study. We proposed that the possible reasons might be the restrictive transfusion policy both in CPB circuit priming (only in patients with an estimated nadir $\mathrm{HCT} \leq 25 \%$ during $\mathrm{CPB}$ ) and after surgery (only in patients with $\mathrm{Hb} \leq 7 \mathrm{~g} / \mathrm{dL}$ or coagulation dysfuction), and routine use of ultrafiltration 
Table 2 Perioperative changes of plasma gelsolin and total protein levels

\begin{tabular}{|c|c|c|c|c|}
\hline & Total & ALI $(n=27)$ & Non-ALI $(n=50)$ & $p$ \\
\hline \multicolumn{5}{|l|}{ Before CPB (a) } \\
\hline $\mathrm{TP}(\mathrm{g} / \mathrm{L})$ & $62.4 \pm 5.6$ & $59.3 \pm 5.6$ & $64.1 \pm 4.8$ & $0.01^{\mathrm{a}}$ \\
\hline pGSN (mg/L) & $157.8 \pm 52.8$ & $122.6 \pm 24.6$ & $176.4 \pm 54.5$ & $0.01^{\mathrm{a}}$ \\
\hline $\operatorname{pGSN}_{N}\left(10^{-3}\right)$ & $2.51 \pm 0.84$ & $2.02 \pm 0.39$ & $2.77 \pm 0.89$ & $0.01^{\mathrm{a}}$ \\
\hline \multicolumn{5}{|l|}{ After CPB (b) } \\
\hline TP $(g / L)$ & $55.1 \pm 4.6$ & $55.3 \pm 4.9$ & $55.0 \pm 4.7$ & $0.81^{a}$ \\
\hline pGSN (mg/L) & $138.7 \pm 51.9$ & $133.2 \pm 54.0$ & $141.7 \pm 51.2$ & $0.53^{\mathrm{a}}$ \\
\hline $\operatorname{pGSN}_{N}\left(10^{-3}\right)$ & $2.52 \pm 0.92$ & $2.41 \pm 0.95$ & $2.33 \pm 0.98$ & $0.11^{\mathrm{a}}$ \\
\hline \multicolumn{5}{|c|}{2 hours after CPB (c) } \\
\hline $\mathrm{TP}(\mathrm{g} / \mathrm{L})$ & $56.6 \pm 5.2$ & $54.9 \pm 4.9$ & $57.5 \pm 5.1$ & $0.08^{\mathrm{a}}$ \\
\hline pGSN (mg/L) & $152.0 \pm 73.7$ & $142.9 \pm 66.9$ & $156.8 \pm 77.6$ & $0.65^{a}$ \\
\hline$p G S N_{N}\left(10^{-3}\right)$ & $2.33(1.26 \sim 0.76)$ & $2.62 \pm 1.24$ & $2.747 \pm 1.35$ & $0.23^{\mathrm{a}}$ \\
\hline \multicolumn{5}{|c|}{6 hours after CPB (d) } \\
\hline TP $(g / L)$ & $56.9 \pm 5.8$ & $55.6 \pm 6.6$ & $57.6 \pm 4.9$ & $0.22^{\mathrm{a}}$ \\
\hline pGSN (mg/L) & $124.3 \pm 47.8$ & $89.9 \pm 17.6$ & $141.0 \pm 49.0$ & $0.01^{\mathrm{a}}$ \\
\hline $\operatorname{pGSN}_{N}\left(10^{-3}\right)$ & $1.80(1.15 \sim 4.63)$ & $1.61 \pm 0.26$ & $2.18 \pm 0.75$ & $0.04^{\mathrm{a}}$ \\
\hline \multicolumn{5}{|c|}{12 hours after CPB (e) } \\
\hline $\mathrm{TP}(\mathrm{g} / \mathrm{L})$ & $58.0 \pm 4.6$ & $55.7 \pm 3.7$ & $59.1 \pm 4.7$ & $0.01^{\mathrm{a}}$ \\
\hline pGSN (mg/L) & $135.9 \pm 54.0$ & $121.3 \pm 38.3$ & $142.5 \pm 59.1$ & $0.33^{\mathrm{a}}$ \\
\hline $\operatorname{pGSN}_{N}\left(10^{-3}\right)$ & $2.34 \pm 0.91$ & $2.19 \pm 0.73$ & $2.41 \pm 0.98$ & $0.40^{\mathrm{a}}$ \\
\hline \multicolumn{5}{|c|}{24 hours after CPB ( $f$ ) } \\
\hline TP $(g / L)$ & $58.1 \pm 5.4$ & $57.7 \pm 4.8$ & $58.3 \pm 5.7$ & $0.71^{\mathrm{a}}$ \\
\hline pGSN (mg/L) & $124.6 \pm 43.9$ & $133.0 \pm 58.2$ & $121.0 \pm 36.5$ & $0.37^{\mathrm{a}}$ \\
\hline $\operatorname{pGSN}_{N}\left(10^{-3}\right)$ & $2.16 \pm 0.75$ & $2.31 \pm 0.87$ & $2.09 \pm 0.69$ & $0.98^{\mathrm{a}}$ \\
\hline \multicolumn{5}{|c|}{48 hours after CPB (g) } \\
\hline $\mathrm{TP}(\mathrm{g} / \mathrm{L})$ & $60.1 \pm 5.8$ & $61.3 \pm 5.3$ & $60.4 \pm 6.2$ & $0.61^{\mathrm{a}}$ \\
\hline pGSN (mg/L) & $123.1 \pm 39.8$ & $111.7 \pm 27.0$ & $129.5 \pm 44.6$ & $0.14^{a}$ \\
\hline $\operatorname{pGSN}_{N}\left(10^{-3}\right)$ & $2.05 \pm 0.74$ & $1.80 \pm 0.45$ & $2.19 \pm 0.83$ & $0.33^{\mathrm{a}}$ \\
\hline \multicolumn{5}{|c|}{72 hours after CPB (h) } \\
\hline $\mathrm{TP}(\mathrm{g} / \mathrm{L})$ & $64.4 \pm 7.2$ & $66.2 \pm 7.7$ & $63.1 \pm 6.6$ & $0.18^{\mathrm{a}}$ \\
\hline pGSN (mg/L) & $131.2 \pm 39.6$ & $124.6 \pm 37.8$ & $136.4 \pm 41.3$ & $0.33^{\mathrm{a}}$ \\
\hline $\operatorname{pGSN}_{N}\left(10^{-3}\right)$ & $2.02 \pm 0.63$ & $1.92 \pm 0.55$ & $2.08 \pm 0.67$ & $0.31^{\mathrm{a}}$ \\
\hline
\end{tabular}

Data were expressed as the mean \pm SD or median (interquartile range) if appropriated.

a: ANCOVA.

$\mathrm{TP}=$ plasma total protein amount; $\mathrm{pGSN}$ = plasma gelsolin; $\mathrm{pGSN}_{\mathrm{N}}=$ plasma gelsolin normalized by plasma total protein amount.

and $\mathrm{CPB}$ circuit residual blood salvage re-infusion in all the patients. Consistent with other age-match population, the patients with CPB-ALI of this cohort did need longer mechanical ventilation and ICU-stay time than patients without ALI, which may related to addition lung fluid retention, delayed recovery of ability of gas exchange and lung mechanics, infectious or noninfectious pulmonary complications, susceptibility to low cardiac output syndrome and other institutional and practice guidelines $[25,26]$. The prognosis of patients with CPB-ALI in this study was good without hospital death and with similar duration of hospital stay in both groups.

For the systemic inflammatory response was proposed to play a pivotal role in the pathogenesis of CPB-induced acute lung injury [27,28], various of factors concerned inflammation, not only the changes in the levels, but also the time courses or the patterns of release, had been described for the affecting the incidence, severity and clinical outcome of the CPB-ALI such as IL-6, IL-8, TNF- $\alpha$ and endotoxins et al. Recent studies highlighting the novel 

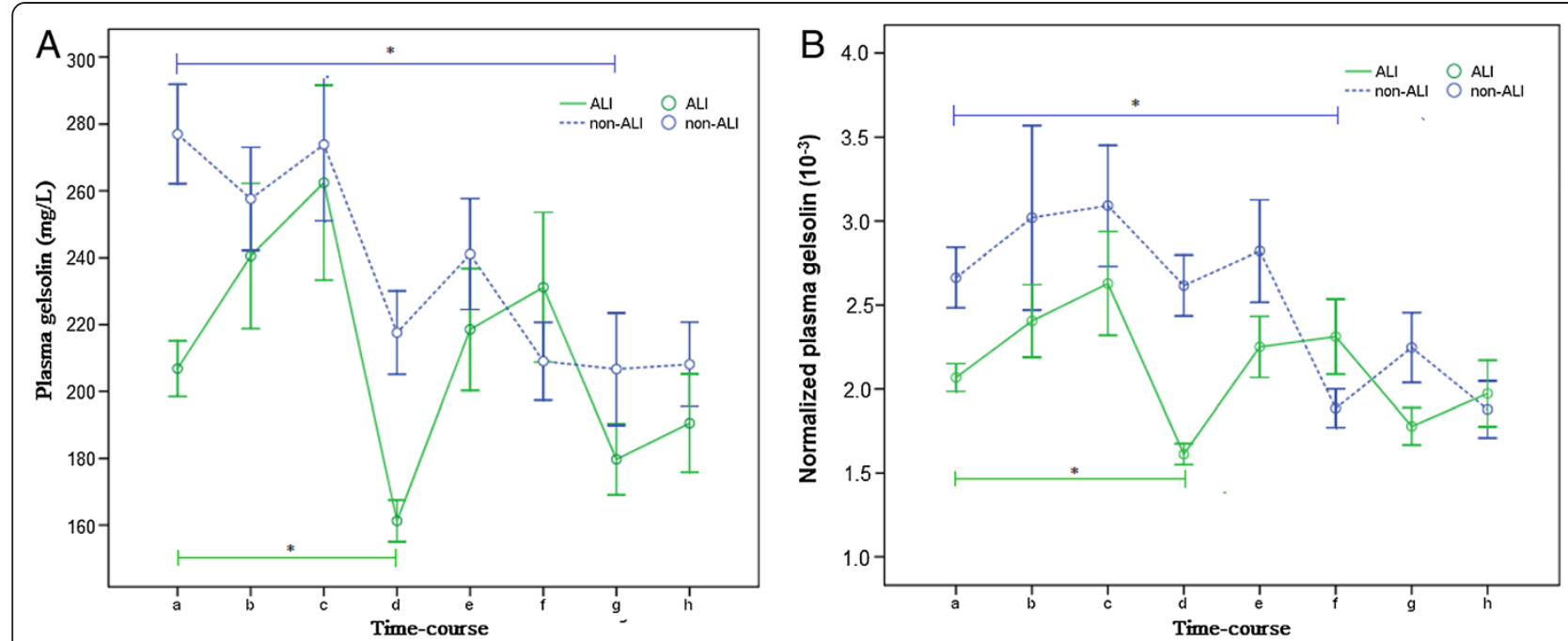

Figure 1 The time course of plasma gelsolin. A: Perioperative change of PGSN levels in ALI (green line) and non-ALI groups (blue line); B: Perioperative change of $\mathrm{PGSN}_{N}$ levels in ALI and non-ALI groups; ${ }^{*}$ Two-way ANOVA, $p<0.05$ versus before CPB (baseline level).

early biomarks of CPB-ALI were performed, such as surfactant derived protein $B(\mathrm{SPB})$ and plasma receptor for advanced glycation end products (RAGE), and have shown to be a promising diagnostic method in both adult and pediatric population [29,30]. Though, the change of pGSN in acute lung injury was still controversial for the differences of etiologies, study kinetic and damage severity. As a novel inflammatory mediator, declining pGSN had demonstrated its predictor and therapeutic value in several acute lung injury model related to SIRS, such as sepsis, burn and trauma [31-33]. In this study, we observed the time course characteristics of pGSN of patients undergoing open heart surgery with $\mathrm{CPB}$, and its role in predicting the occurrence and severity of CPB-ALI.
The total baseline level of pGSN (preoperative level) in this study was $(157.8 \pm 52.8) \mathrm{mg} / \mathrm{L}$, which was much lower than of that of adult population of $190-300 \mathrm{mg} / \mathrm{L}$ [34]. And the baseline level of pGSN of ALI patients was significantly lower than that of patients without CPB-ALI [(122.6 \pm 24.6$) \mathrm{mg} / \mathrm{L}$ vs. $(176.4 \pm 54.5) \mathrm{mg} / \mathrm{L}, p<0.01]$. This meant that patients with lower plasma gelsolin "reservoir" were more prone to acute lung injury after CPB, and lower preoperative pGSN level might be a possible early predictor of CPB-ALI [15-18,35]. In addition, for recombinant pGSN is available, gelsolin supplement could be a safe and promising therapy in preventing and alleviating $\mathrm{CPB}$-ALI before surgery in the future. We also found that both pGSN and $\mathrm{pGSN}_{\mathrm{N}}$ of ALI group decreased
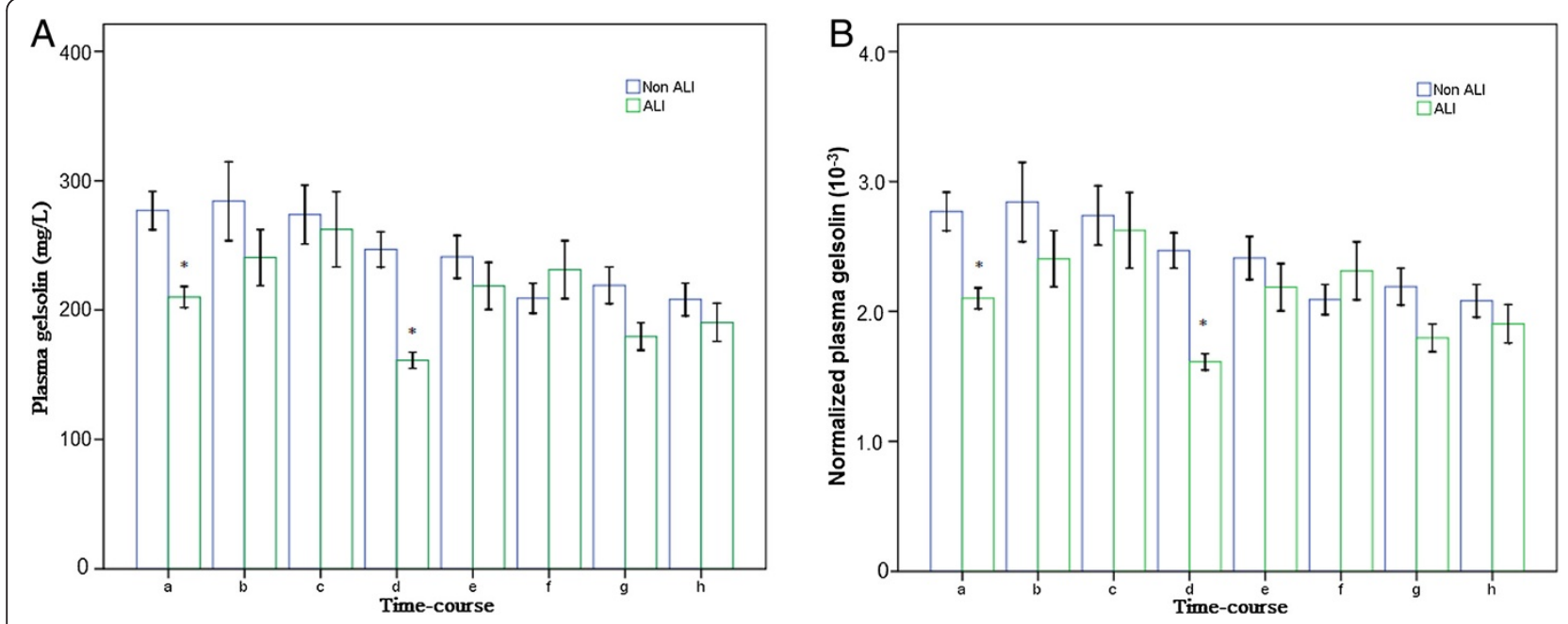

Figure 2 The comparison of plasma gelsolin between two groups. A: The comparison of pGSN levels between two groups at each time point; $\mathbf{B}$ : The comparison of $\mathrm{pGSN}_{N}$ levels between two groups at each time point; ${ }^{*} \mathrm{ANCOVA}, p<0.05$. 


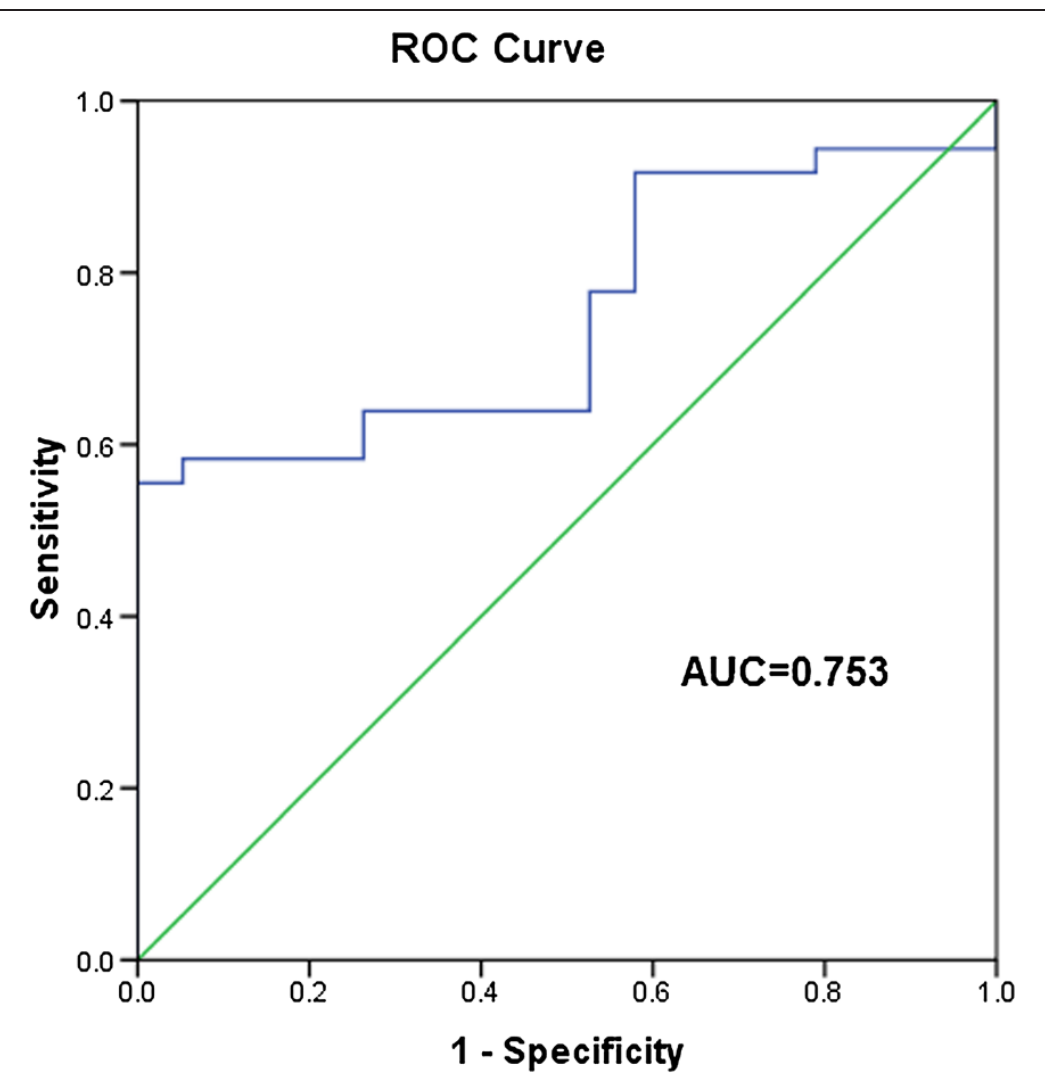

Figure 3 ROC curve for pGSN before CPB. The AUC of pGSN before CPB for CPB-ALI was 0.753 (95\%Cl, 0.626 to 0.880 ).

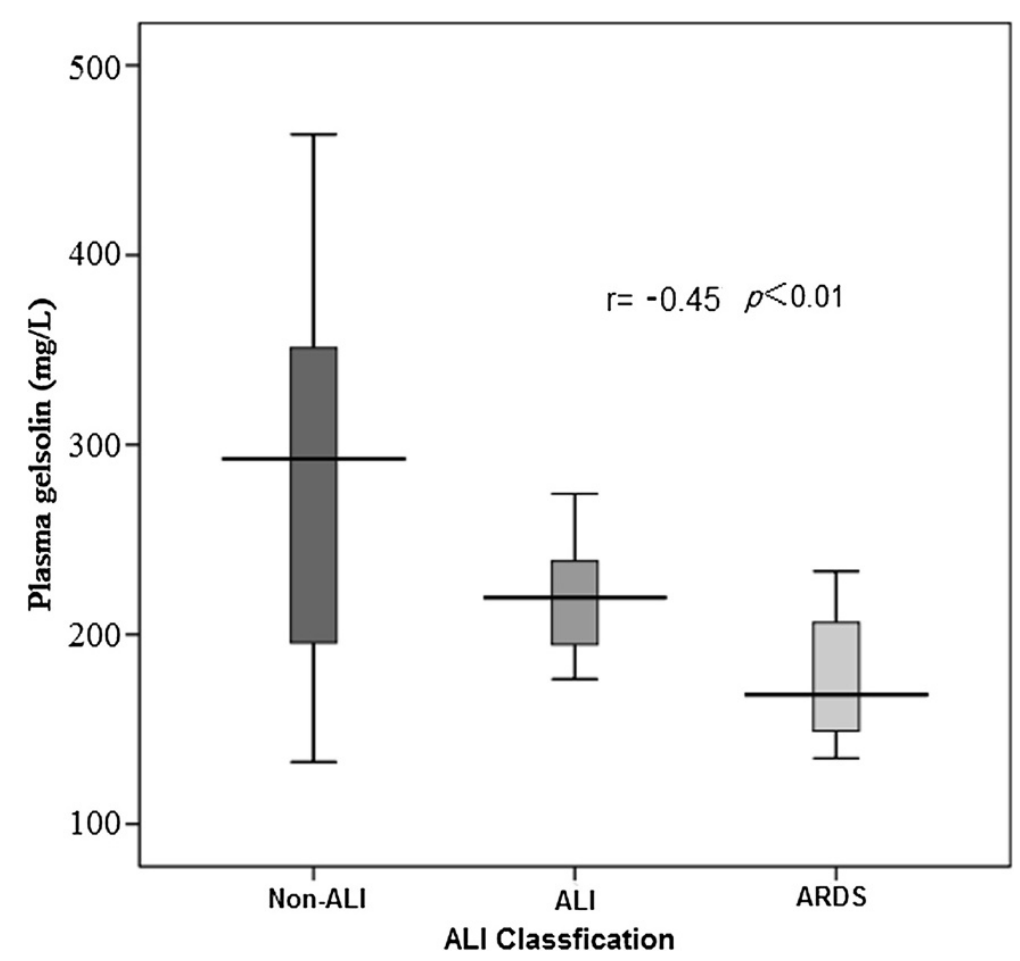

Figure 4 The severity of CPB-ALI. PGSN before CPB was significantly negative correlated with the severity of CPB-ALI in this study $(r=-0.45, p<0.01)$. 
significantly at 6 hours after $\mathrm{CPB}$, which were much earlier than those of non-ALI group (48 and 24 hours after CPB); PGSN and $\mathrm{pGSN}_{\mathrm{N}}$ of ALI group at 6 hours after CPB were much lower than those of non-ALI group. The depletion of pGSN was due to the decreased production and increased consumption. Though the production of gelsolin could not be identified for the difference of individuals' muscle mass, we speculated a much more amount and rapid consumption of plasma gelsolin in ALI group for two main reasons. First, pGSN sequestration at lesions or clearance with circulating actin released from damaged and dying cells or tissues is a principal reason for depletion of pGSN. Second, as an inflammatory mediator-binding protein in the circulation, pGSN binds to the quantities of inflammatory mediator and pro-inflammatory cytokines provoked by $\mathrm{CPB}$, as to alleviate the local and systemic inflammatory response.

After collecting all the possible risk factors into final multiple regression analysis, we found that pGSN before $\mathrm{CPB}$ was the only independent risk factor predicting for CPB-ALI (OR, 1.023; 95\% CI, 1.007-1.039; $p<0.01$ ), with an AUC of 0.753 (95\% CI, 0.626-0.880); The optimal cutoff for pGSN before CPB was $264.2 \mathrm{mg} / \mathrm{L}$, with a sensitivity of $58.3 \%$ and a specificity $94.7 \%$. And lower pGSN before CPB was significantly associated with the severity of CPB-ALI in this study (Figure $4, r=-0.45$, $p<0.01$ ). These findings demonstrated that pGSN before CPB could not only be a novel early biomarker for CPB-ALI, but also a reliable quantitative factor reflecting the severity of $\mathrm{CPB}-\mathrm{ALI}$ in infants and young children.

\section{Limitation}

Limitation of the present study should be acknowledged. First, the study was based on a single medical center, local practice patterns, and a small number of patients, which might impede the application of present findings to other institutions. Second, the population of the study was restricted in the patients with CHD below 3-year-old, so we could not be sure whether these findings were available for elder children or adult patients. Third, the gelsolin level in the lung tissue was not detected in the study, therefore, the correlation of gelsolin between site of injury and circulation was still unclear.

\section{Conclusions}

Patients developing CPB-ALI had lower plasma gelsolin reservoir and a much more amount and rapid consumption of plasma gelsolin early after operation. PGSN before $\mathrm{CPB}$ was an early and sensitive predictor of CPB-ALI in infants and young children undergoing cardiac surgery with $\mathrm{CPB}$, and was negatively correlated with the severity of CPB-ALI.

\section{Additional files}

Additional file 1: Guideline for respiratory managements.

Additional file 2: Definitions of clinical variables.

\section{Competing interests}

The authors declare that they have no competing interests.

\section{Authors' contributions}

SSS participated in the design of the study and drafted the manuscript. CC and SJW collected the clinical data and blood samples of the patients, and helped to draft the manuscript. DYZ carried out the statistical analysis and helped to draft the manuscript. BLC and XWL carried out the ELISA test. RL and LHT participated in the design of the study and coordination and helped to draft the manuscript. QS and XMF participated in the design of the study and critical revision of the article for the important content. All authors had read and approved the final manuscript.

\section{Acknowledgments}

This work was financially support by National Natural Science Foundation (ShanShan Shi, 81100050), Foundation of Science Technology Department of Zhejiang Province, China (Qiang Shu, 2011C23011), Military of Education Doctor Station Foundation (Qiang Shu, 20120101110049), Science and Technology Innovation Team of Zhejiang Province (Qiang Shu, 2010R50045), National Science and Technology Support Program (Qiang Shu, 2012BAI04B05) and the National Natural Science Foundation of China (Qiang Shu, 81272139).

\section{Author details}

${ }^{1}$ Surgical Intensive Care Unit, Children's Hospital, Medical College, Zhejiang University, No. 57, Zhugan Lane, Hangzhou 310003, P R China. ${ }^{2}$ Department of Thoracic \& Cardiovascular Surgery, Children's Hospital, Medical College, Zhejiang University, and Zhejiang Key Laboratory for Diagnosis and Therapy of Neonatal Diseases, No. 57, Zhugan Lane, Hangzhou 310003, P R China. ${ }^{3}$ Department of Anesthesiology, the First Affiliated Hospital, Medical College, Zhejiang University, No. 79, Qingchun Road, Hangzhou 310003, P R China.

Received: 15 July 2013 Accepted: 30 July 2014

Published: 7 August 2014

\section{References}

1. Altmay E, Karaca P, Yurtseven N, Ozkul V, Aksoy T, Ozler A, Canik S: Continuous positive airway pressure does not improve lung function after cardiac surgery. Can J Anaesth 2006, 53:919-925.

2. Apostolakis E, Filos K, Koletsis E, Dougenis D: Lung dysfunction following cardiopulmonary Bypass. J Card Surg 2010, 25:47-55.

3. Clark SC: Lung injury after cardiopulmonary bypass. Perfusion 2006, 21:225-228.

4. Santos AR, Heidemann SM, Walters HL, Delius RE: Effect of inhaled corticosteroid on pulmonary injury and inflammatory mediator production after cardiopulmonary bypass in children. Pediatr Crit Care Med 2007, 8:465-469.

5. Shi S, Zhao Z, Liu X, Shu Q, Tan L, Lin R, Shi Z, Fang X: Perioperative risk factors for prolonged mechanical ventilation following cardiac surgery in neonates and young infants. Chest 2008, 134:768-774.

6. Silacci P, Mazzolai L, Gauci C, Stergiopulos N, Yin HL, Hayoz D: Gelsolin superfamily proteins: key regulators of celluar function. Cell Mol Life Sci 2004, 61:2614-2623.

7. Lee WM, Galbraith RM: The extracellular actin-scavenger system and actin toxicity. N Engl J Med 1992, 326:1335-1341.

8. Kwiatkowski DJ, Mehl R, Izumo S, Nadal-Ginard B, Yin HL: Muscle is the major source of plasma gelsolin. J Biol Chem 1988, 263:8239-8243.

9. Bucki R, Byfield FJ, Kulakowska A, McCormick ME, Drozdowski W, Namiot Z, Hartung T, Janmey PA: Extracellular gelsolin binds lipoteichoic acid and modulates cellular response to proinflammatory bacterial wall components. J Immunol 2008, 181:4936-4944.

10. Bucki R, Georges PC, Espinassous Q, Funaki M, Pastore JJ, Chaby R, Janmey PA: Inactivation of endotoxin by human plasma gelsolin. Biochemistry 2005, 44:9590-9597.

11. Matsuoka Y, Saito M, LaFrancois J, Saito M, Gaynor K, Olm V, Wang L, Casey E, Lu Y, Shiratori C, Lemere C, Duff K: Novel therapeutic approach for the treatment of Alzheimer's disease by peripheral administration of agents with an affinity to beta-amyloid. J Neurosci 2003, 23:29-33. 
12. Osborn TM, Dahlgren C, Hartwin JH, Stossel TP: Modifications of cellular responses to lysophosphatidic acid and platelet-activationg factor by plasma gelsolin. Am J Physiol Cell Physiol 2007 292:C1323-C1330.

13. Wang H, Cheng B, Chen Q, Wu S, Lv C, Xie G, Jin Y, Fang X: Time course of plasma gelsolin concentrations during severe sepsis in critically ill surgical patients. Crit Care 2008, 12:R106.

14. Rothenbach PA, Dahl B, Schwartz JJ, O'Keefe GE, Yamamoto M, Lee WM, Horton JW, Yin HL, Turnage RH: Recombinant plasma gelsolin infusion attenuates burn-induced pulmonary microvascular dysfunction. J App Physiol 2004, 96:25-31.

15. Lee PS, Drager LR, Stossel TP, Moore FD, Rogers SO: Relationship of plasma gelsolin levels to outcomes in critically ill surgical patients. Ann Surg 2006, 243:399-403.

16. Jin Y, Li BY, Qiu LL, Ling YR, Bai ZQ: Decreased plasma gelsolin is associated with 1-year outcome in patients with traumatic brain injury. J Crit Care 2012, 27:527. e1-6.

17. Di Nubile MJ, Stossel TP, Ljunghusen OC, Ferrara JL, Antin JH: Prognostic implications of declining plasma gelsolin levels after allogeneic stem cell transplantation. Blood 2002, 100:4367-4371.

18. Suhler $\mathrm{E}$, Lin W, Yin HL, Lee WM: Decreased plasma gelsolin concentrations in acute liver failure, myocardial infarction, septic shock, and myonecrosis. Crit Care Med 1997, 25:594-598.

19. Bernard GR, Artigas A, Brigham KL, Carlet J, Falke K, Hudson L, Lamy M, Legall JR, Morris A, Spragg R: The American-European Consensus Conference on ARDS: definitions, mechanisms, relevant outcomes, and clinical trial coordination. Am J Respir Crit Care Med 1994, 149:818-824.

20. Hatakeyama N, Matsuda N: Mechanisms of Inflammatory Response and Organ Dysfunction: Organ-Protective Strategy by Anesthetics. Curr Pharm Des 2014. doi:10.2174/1381612820666140204105229.

21. Cox CM, Ascione R, Cohen AM: Effect of cardiopulmonary bypass on pulmonary gas exchange: a prospective randomized study. Ann Thorac Surg 2000, 69:140-145.

22. Vlaar AP, Hofstra JJ, Determann RM, Veelo DP, Paulus F, Levi M, Zeerleder S, Vroom MB, Schultz MJ, Juffermans NP: Transfusion-related acute lung injury in cardiac surgery patients is characterized by pulmonary inflammation and coagulopathy: A prospective nested case-control study. Crit Care Med 2012, 40:2813-2820.

23. Vlaar AP, Juffermans NP: Transfusion-related acute lung injury: a clinical review. Lancet 2013, 382:984-994.

24. Bjursten H, Al-Rashidi F, Dardashti A, Brondén B, Algotsson L, Ederoth P: Risks associated with the transfusion of various blood products in aortic valve replacement. Ann Thorac Surg 2013, 96:494-499.

25. Canet J, Gallart L, Gomar C, Paluzie G, Valle's J, Castillo J, Sabaté S, Mazo V, Briones Z, Sanchis J, ARISCAT Group: Prediction of postoperative pulmonary complications in a population-based surgical cohort. Anesthesiology 2010, 113:1338-1350.

26. Gajic O, Afessa B, Thompson BT, Frutos-Vivar F, Malinchoc M, Rubenfeld GD, Esteban A, Anzueto A, Hubmayr RD: Prediction of death and prolonged mechanical ventilation in acute lung injury. Crit Care 2007, 11:R53.

27. Sievers $H$, Freand $K$, Eleftheriadis $S$, Fischer $T$, Kuppe $H$, Kraatz EG, Bechtel JF: Lung protection during total cardiopulmonary bypass byisolated lung perfusion: result sofanovel perfusions tratery. Ann Thorac Surg 2003, 76:516-521

28. Suzuki T: Additional lung-protective perfusion techniques during cardiopulmonary bypass. Ann Thorac Cardiovasc Surg 2010, 16:150-155.

29. Agostoni P, Banfi C, Brioschi M, Magrì D, Sciomer S, Berna G, Brambillasca C, Marenzi G, Sisillo E: Surfactant prtein B and RAGE increase in the plasma during cardiopulmonary bypass: a pilot study. Eur Respir J 2011, 37:841-847.

30. Liu X, Chen Q, Shi S, Shi Z, Lin R, Tan L, Yu J, Shu Q, Fang X: Plasma sRAGE enables prediction of acute lung injury after cardiac surgery in children. Crit Care 2012, 16:R91.

31. DiNubile MJ: Plasma gelsolin levels in the diagnosis, prognosis, and treatment of lung complications of prematurity. Am J Respir Crit Care Med 2012, 186:1195-1196.

32. Christofidou-Solomidou M, Scherpereel A, Solomides CC, Muzykantov VR, Machtay M, Albelda SM, DiNubile MJ: Changes in plasma gelsolin concentration during acute oxidant lung injury in mice. Lung 2002, 180:91-104
33. Maniatis NA, Harokopos V, Thanassopoulou A, Oikonomou N, Mersinias V, Witke W, Orfanos SE, Armaganidis A, Roussos C, Kotanidou A, Aidinis V: A critical role for gelsolin in ventilator-induced lung injury. Am J Respir Cell Mol Biol 2009, 41:426-432.

34. Kwiatkowski DJ, Stossel TP, Orkin SH, Mole JE, Colten HR, Yin HL: Plasma and cytoplasmic gelsolins are encoded by a single gene and contain a duplicated actin-binding domain. Nature 1986, 323:455-458.

35. Chavko M, Prusaczyk WK, McCarron RM: Lung injury and recovery after exposure to blast overpressure. J Trauma 2006, 61:933-942.

doi:10.1186/1471-2253-14-67

Cite this article as: Shi et al:: The role of plasma gelsolin in cardiopulmonary bypass induced acute lung injury in infants and young children: a pilot study. BMC Anesthesiology 2014 14:67.

\section{Submit your next manuscript to BioMed Central and take full advantage of:}

- Convenient online submission

- Thorough peer review

- No space constraints or color figure charges

- Immediate publication on acceptance

- Inclusion in PubMed, CAS, Scopus and Google Scholar

- Research which is freely available for redistribution 